\title{
Effect of Use of Scientific Calculators on Yamfo Anglican Senior High School Students' Mathematical Achievement
}

\author{
Adam Mumuni Jeremiah
}

\begin{abstract}
This study investigated the effect of use of scientific calculators on Yamfo Anglican Senior High School Students mathematical achievement. The main instrument were tests (pre-test and post-test) and questionnaire designed to collect data which were analyzed using quantitative methods and qualitative method. The sample size for the study was 41 students. A dependent sample t-test was conducted to compare the difference between students' ability to solve mathematical questions by using calculator and not using calculator. The results indicated there was a statistically significant difference in students' performances in solving mathematical questions in the first achievement test $(M=40.78, S D=17.984)$ and second achievement test $(M=51.58, S D=17.984)$ respectively $[t(39)=$ 25.206, $p=.000]$. This result implied the intervention was successful; the students improved in their understanding of the use of the scientific calculator and improved their computational skills in mathematics such as sequence of operations, approximations, application of concepts and the appropriate use of parenthesis. Students most errors in the pre - test were on parenthesis, followed by operational sequence, approximations and concept applications which were overcome by the intervention.
\end{abstract}

\section{INTRODUCTION}

Performance in mathematics is very crucial for admission of students into various institutions of higher learning in the country, such as Colleges of Education, Polytechnics and Universities to mention but a few. Apart from the economic benefits of better preparing young people for the numeracy demands of modern work place and raising the overall skill levels of the work place, there are also social benefits tied to improving access for larger numbers of young people and laying stronger foundation on skills for life-long learning.

Other organizations have suggested the importance of integrating technological tools such as computers and calculators into instructional practice to improve mathematics learning and students' performance(National Research Council (NRC), 1989); British Broadcasting cooperation, 2006).There is research evidence (Shamatha, Peressini \& Meymaris, 2004; Wu, An, \& Wan 2005) which said that the use of calculators in instructions could impact positively both on the teachers' and students' attitude towards mathematics instruction and learning respectively. Accepting calculators and computers as instructional tools would engage learners in their own construction of knowledge through exploration of mathematical processes and ideas; teachers also would have the opportunity to enhance their own learning of mathematics (The Association of Mathematics Teacher Educator's (AMTE), 2006).

Nabie and Yidana (2001), enumerated some uses of the calculator to both the learner and the teacher. They said that if instructional time is properly managed to provide children the opportunity to use the calculator in their learning process, it will enable them to "practice basic skills, do investigation through which they generate patterns, explore mathematical properties and make hypothesis, improve their skills, use mathematics in real life situation and in other subjects, understand and facilitate concept formation encourage discovery and do complex computations". To the teacher, it will help to diagnose and remedy children's learning difficulties in specific concepts and skills and use calculators as teaching aids and help save time and energy. According to Hunter (2011), reasoning is one important component of students' mathematical learning and conceptual understanding in mathematics. There are several skills important to the understanding of maths, of which reasoning is one. It has been suggested that student use of graphing calculators and computers can improve student success in areas such as concept development and problem solving while providing opportunities for visualization, access to multiple representations and computation (NCTM, 2000).

Computational skills are skills that are used in engaging a task whose solution is not readily known. The computational skills include estimating, appropriate use of parenthesis, computational speed, correct use of sequence of operations and approximation. All these skills are used in solving mathematical problems when using scientific calculators.

Computations are complex physical activities which involve a number of processes such as problem representation and problem execution. The two main stages demand that students have computational skills to solve mathematical problems.

Calculators serve a similar function in mathematics classroom as a word processor does in language arts. A word processor cannot "create" an essay but it does help significantly in the creation of an essay. A calculator cannot understand a mathematical problem but it can help significantly in the solution of the mathematical problem. 


\section{STATEMENT OF THE PROBLEM}

Following the success of Ghana's first Information, Communication Technology (ICT) week in 2003, the second forum witnessed extensive presentations such as the role of ICT in education as the bedrock for sustainable national development (Turner \& Yidana, 2004). Even though, a curriculum for ICT training and examinations at high school level has been put in place, yet there is no mention of a policy towards the use of calculators in mathematics instructions and learning. The use of calculators for high school students is only for computational purposes but not incorporated into instructions for conceptual understanding. There is a restriction to the type of calculator's Ghanaian students can use during examination. The type of calculators permitted by West Africa Examination Council is limited to only fx991E, scientific calculator, though its usage is very complex.

According to West Africa Examination Council (2014) Supervisors should inspect all electronic calculators and ensure that they conform to the following specifications: They should be silent, cordless, and non-programmable and must be dry cells or solar energy only, must not have facility for magnetic card input or plug-in modules of programme instructions and should not have paper-type output. Hence students are not permitted to use graphical calculators in examination hall. With the Basic Education Certificate Examination students are not permitted to use calculators at all. My personal observation shows that a considerable proportion of Ghanaian teachers would not be inclined to adapt to technological advances in mathematics instructions and much less encouraging the use of calculators among their students. This is because they lack basic skills on its usage, such as using some key functions, introducing calculators in such a system could be met with some form of resistance.

"Many students have lost the ability to do pencil and paper or mental calculation and it is to their detriment. Even for the simplest computation, students immediately turn to the calculator and if the teacher says to them you may not use the calculator, many of them will be lost, they cannot proceed". (Lord, 2003, p.13). More disturbing is the fact that from the Chief Examiners Report on the Core Mathematics of West African Senior School Certificate Examinations (WASSCE) indicated students' performance in school certificate examination in mathematics was weak particularly in computation and problem solving (WAEC, 2008).

Furthermore, the results from trends in International Mathematics and Science Study (TIMSS) conducted for Junior Secondary year two (grade8) in 2007 and 2011 respectively, mathematics average score of 309 and 331 respectively for grade 8 students from Ghana were lower than the low international benchmark average of 400 (Mullis, Martin \& Foy, 2008; Mullis, Martin, Foy \&Arora, 2012). Most participation countries in TIMSS, have successfully integrated calculators in their instructional practices.

The problem is, Yamfo Anglican High School Students have difficulties in using some key functions of the calculator which affect their computational skills.

\section{Purpose of the Study}

The study aimed at establishing the impact of the use of scientific calculator on Yamfo Anglican Senior High School form three students' computational skills and find difficulties and perceptions students of Yamfo Anglican Senior High School have in using the calculator.

\section{Research Questions}

- What effect does the use of the calculator have on Yamfo Anglican Senior High School Students' computational skills?

- What difficulties do Students of Yamfo Anglican Senior High School have in using the calculator?

- How do Students' of Yamfo Anglican Senior High School perceive the use of calculators in mathematics?

\section{Significance of the Study}

The study was significant in a number of ways: It would form a basis for the government of Ghana, Educational policy planners, The curriculum research development division (CRDD), ministry of Education, Ghana Education Service Council, various umbrella organizations such as GNAT, NAGRAT, Coalition for Concern Teachers Associations, Chiefs, Parents and Students to assume a more positive move to ensure that Students of Yamfo Anglican Senior High in the Tano North District of Ghana, re- think of the proper use of the calculator to motivate students to have interest in learning mathematics.

\section{LITERATURE REVIEW}

\section{Calculator Usage in Schools}

The idea of 'mental maths' would help to teach students not to depend on their calculators: it teaches them that they can use a calculator as a tool instead of as a crutch. Children need not to grow up with this idea, so later in school they would not have a hard time learning mathematical concepts. The use of calculator in teaching Mathematics

Bayetto and Yate, (2009) are of the view that increasing numbers of calculators have become available in schools as indicated in their research. Studies indicated that they were underutilized as teaching resources for all students in mathematics classrooms. Furthermore, I am of the view that many teachers continue to fear that traditional skills would not be learnt if calculators are used and that students will be 
over-reliant on them and access to scientific calculators gives an unfair advantage and is a form of cheating.

Currently, there is much interest and debate concerning the role, nature, and place of calculators in the teaching and assessment in the school system, especially in the senior high schools. The calculator may be useful in developing and consolidating a concept; however, it may not always be appropriate or essential in assessing that concept. The National Council of Teachers of Mathematics (NCTM) in North America, Technology principle states; technology is essential in teaching and learning mathematics; it influences the mathematics that is taught and enhances student's learning (NCTM 2000,page24).Currently research in technology and mathematics education has found "electronic technologies - calculators and computers -are essential tools for teaching, learning and doing mathematics and students can learn more mathematics deeply with the appropriate use of technology. In many problem situations, calculator free students from tedious calculations so that valuable classroom time can be spent on higher order thinking and reasoning.

"Already in Florida, students schooled in largely calculator - friendly maths courses are scoring poorly on states college maths placement test which does not allow the use of calculators. Students must score higher than a 72 mark on the elementary algebra test to avoid being placed in remediation score which hovered in the mid 50's for the past five years" (Catalanello,2003 p1.). It seems to be a very good idea not to permit the use of calculators on test, but it does pose a slight problem. The test score will probably decrease for a short period of time. You cannot just take away the calculators from the students after every one has been using them through-out their entire schooling. The calculators need to be used less, starting at a young age. Then when the calculators are used later, when the students are older, it should only be used as a tool to assist them. It is important to teach students how to do mathematics with calculators. But they should also be required to learn how to multiply $23 * 37$ and to solve $4 x=2 x+10$ the old-fashioned way without the aid of calculators (Dancis, 2004). It is important for students to learn the basic concepts and when they have mastered them then they should be able to use a calculator more often.

It was mentioned that the recent Anamuah-Mensah Educational review committee (2002), introduced a lot of changes markedly to improve the curriculum, making it relevant to the demands of this fast-changing world, with the inclusion of very pertinent topics which hitherto were not part of the syllabus. One of the obvious changes was the inclusion in the Junior High School (JHS) mathematics curriculum, the introduction to the use of calculators in JHS1 mathematics syllabus as the seventh topic. This change must be commended in two ways; with the introduction of ICT as a subject, students need to be familiar with simple gadgets like calculators and also when students are introduced to calculators at the JHS level it becomes easier for Senior High School (SHS) mathematics teachers to introduce other higher functions of calculators to students therefore making the transition very smooth. In this technological era, in our daily lives, calculator computations have become more popular than paper and pencil computations.

However, paper and pencil methods still receive the most emphasis in schools. The emergence of calculators and computers serve to highlight the lack of congruence between school mathematics and real mathematics, (Willis \&Kissane, 1989, P.58). It is known that our society is changing and that we live in a world that is dominated by information. Each day, students come across graphs, dealing with large numbers and statistics and technology has become an important part of our daily lives. The change in the mathematics curriculum was needed because of the fastchanging world. This fact was attested for by the eighth aim of the new mathematics syllabus in Ghana (2007) which states that "use the calculator and computer for problem solving and investigation of real-life situations" P (ii).

With the introduction of calculators at JHS, one was of the view that calculators would be allowed into the examination halls, but students are still barred from using calculators for the Basic Education Certificate Examination (BECE). Students are not allowed to use calculators even in their various schools for class exercises let alone their end of term examination. Why JHS students are introduced to calculators and are denied their use during examination at school and national levels? There is a missing link somewhere which must be found.

\section{Difficulties Students Encounter when Using the Calculator}

Although research supports the claim that calculators use improves students' performance in computation, concept development and problem-solving, studies show that there are a class of errors and misconceptions that are induced by calculators. Also, calculators can be potentially subversive and will undermine students' confidence with number paper and pencil calculations if not properly used. (Mereku et al, 2007, p.59).

Some of the errors made by students using calculators include not being familiar with how to change modes, forgetting to write down calculations to get method and accuracy marks. And checking all calculations in case of pressing a wrong button, rounding values too soon, instead of values rounded only at the end of the calculations, not storing calculations in the memory to get them back when necessary and forgetting to use brackets on divisions for 
example when dividing by the denominator of a fraction. A calculator diminishes the need for students to acquire a high degree of skills in symbol manipulation. Students tended to use their calculators as private devices which often led to the breakdown of group interactions (Doerr \& Zangor, 2000. P158). This seems reasonable because students could be at different stages of the problem, based on their ability. Students seldom guess what the calculator says and feel free to continue without verification from the group.

According to Frances (2010), some students struggle with economics because they do not fully understand the mathematical tools economists used. Some teachers find it difficult to know, what their students do not know, and have no idea how to help them bridge those gaps. But it is very simple for students under certain age to be drilled in mental maths which they have not been. Another aspect of the mental arithmetic gap that is easily over looked is its widening over time. Students in the 1980s were taught by teachers who had learned mathematics without calculators and could do basic mental arithmetic. Students today might be taught by a teacher who is himself unable to work out $37+16$ without help. Recent research is suggesting that deep understanding of mathematical concepts is related to basic number sense. A person who can look at two sets of dots and quickly determine which set is larger will also generally be better at abstract, conceptual, mathematical reasoning. Graphing the production function $\mathrm{f}(\mathrm{x})=\operatorname{In}(\mathrm{x})$ by entering the function into a graphic calculator and copying down the results just seems like cheating.

The researcher thinks there is a lot of intuition that can be gleaned from bottom up approach that emphasizes basic skills. During these rote exercises the mind searches for shortcuts and much intuition and insight can be gained moments when you find a way to shorten the exercise with a trick of some sort. For instance, to multiply any single digit number by nine, just add a zero to the end and subtract the number. Thus $8 * 9$ must be $80-8=72$.or $4 * 9=40-4$. Then its easy to generalize, 9 times any two-digit number is the number with a zero attached minus the number. Thus $28 * 9=280-28=252$, or $9 * 32=320-32=288$. Then extend further; it works for a single digit time's numbers of any size. Four digits would be $9 * 1234=12340-1234=11,106$. Something you can do relatively easy in your head (Frances, 2010). I plan to remain hard - headed about this until I am convinced that abandoning the rote sorts of exercises done in, say a linear algebra class (which can be on a calculator) does not hinder our ability to form intuition about how to do proof etc. And these skills are valuable in other settings as well. I do not know how many times written computer programmes can be shortened and made much more elegant by exploiting the patterns that emerge in the brute programme and that usually leads to a very impact, linear algebra representation of the programme (which can lead to further insights about the underlying statistical model). The inductive type reasoning that emerges from these exercises is valuable in many settings - I would guess learning to find patterns is a skill that is useful beyond pure mathematics and worry that an over reliance on calculators will rode the development of these skills. I am absolutely convinced, for example, that forcing people to do econometrics and statistical exercises by hand develops intuition that you cannot get any other way and this is a key to moving on to doing proofs. (Frances, 2010).

Reasoning is defined by the (NCTM 1989.) as "The process of drawing conclusions on the basis of evidence or stated assumptions". Sense making is defined as "developing understanding of a situation, context, or concepts by connecting it with existing knowledge" (NCTM 1989.). The processes of reasoning and sense making are said to be intertwined as students can make sense of mathematical concepts as they engage in reasoning. The NCTM (1989) suggests that including opportunities for reasoning and sense making in the mathematics curriculum will help students to have a better understanding of mathematical procedures, when they are used, what they mean and why they work. Likewise, mathematics should make sense and have meaning to students. In addition, students are only able to make sense of mathematics if they have an understanding of the concepts involved. Concepts are said to be "the substance of mathematical knowledge" (NCTM, 1989, P233). Mathematical reasoning helps students think logically and make sense of mathematics. Students need to develop confidence in their abilities to reason and justify their mathematical thinking. High- order questions challenge students to think and develop a sense of wonder about mathematics. Mathematical experiences in the classroom provide opportunities for students to develop their ability to reason. Students can explore and record results, analyze observations, make and test generation, from patterns and reach new conclusions by building upon what is already know or assumed to be true.

Reasoning skills allow students to use a logical process to analyze a problem, reach a conclusion and justify or defend that conclusion

10 Advantages of the Calculator

The calculator is valuable tool for exploration and discovery in problem - solving situations and when introducing new mathematical content, by reducing computational time and providing immediate feedback, calculators help students focus on understanding their work and justifying their methods and results. The calculator is particularly useful in helping to illustrate and develop concepts and in making connections between algebraic and geometric ideas, in order to accurately reflect their meaningful mathematics 
performance; Students should be allowed to use their calculators in achievement tests and teachers should also use the scientific calculators during instruction. Not to do so is a major disruption in many students' usual way of doing mathematics and an unrealistic restriction because when they are away from the school setting, they will certainly use a calculator in their daily lives and in their work place.

However, mental arithmetic is really important in our environment. In fact, with all the changes and improvement in technology it is really important to let our students learn about maths in the right way - the arithmetic way. In Ghana, a strong movement towards the improvement of students' mathematics curriculum has been recently launched. This government project aims to make maths a priority in schools. The president of the Ghana mathematics society, Anku (2011), said that the need is to enable learners or students to enjoy learning maths and help them realize that it plays an important role in society. He also said that mental arithmetic is an essential aspect of life and that it is a good idea to build their school maths curriculum around it for the students' future. In fact, some students do not graduate into higher studies because they have failing scores in mathematics.

It was also observed that some people who wanted to try out for the Ghana Armed forces, The National Security Services and Nursing Training College or other professions did not pass the mathematics proficiency test. Anku (2011), appealed to the media to help them in this project by showing programmes that teaches mathematics.

Gordon (2011), Director General of the Ghana - Indian Kofi Annan Centre for Excellence in ICT also appealed to Ghana educators to think of other method to teach mathematics.

The reason for restricting the use of calculators in introductory maths and science class is that students were beginning to lose the ability to do mental mathematics and it will be no help in higher math classes and can be an active impediment to learning. This fact was further buttressed by Education and Childcare Minister Trust. According to Luara (2012) announced that calculators would be banned in mathematics tests for 11year - old from 2014. Ten - year olds in England are among the highest users of calculators in the World $-98 \%$ are allowed to use them in maths lessons, according to the trends in international mathematics and science study (TIMSS) in 2007. This compares to the international average of $46 \%$ of 10 - years - olds allowed to use them in classes. She said that as a results children were not getting the rigorous grounding in mental and written arithmetic they needed to progress. She warned that pupils were using calculators too much and too soon at primary school - the current curriculum suggests introducing them at seven. The draft primary programme of study published last June was clear that calculators should not be introduced until late primary. That is, calculators should be introduced only when pupils were confident in basics, such as knowing times tables off by heart and understood the methods to add, subtract, multiply and divide. It is important that calculators are used appropriately, so children do not become dependent on them for arithmetic but at the same time are able to use them as a tool to support their own problem solving. Technology is reminiscent of a train coming down the tracks with full head steam and there is nothing that can be done to stop it. One can either get on board or be run over by technology. But technology should not be used as a replacement for basic understanding and intuitions; rather, it can and should be used to foster those understandings and intuitions. In mathematics instruction programmes, technology should be used widely and responsibly, with the goal of enriching students learning of mathematics.

\section{METHOD}

\section{Research Design}

The study employed an action research design. According to Cannae (2004), "action research "involves the application of scientific methods to solve classroom problem. This design has been chosen because the researcher identified a problem with the form three students of Yamfo Anglican Senior High School. The researcher thought it wise to help the students to reduce their difficulties in the use of scientific calculator. According to Miller (2007), action research is a natural point of teaching. Teachers are continually observing students, collecting data and changing practices to improve students' learning in the classroom and school environment. Action research provides a frame work that guides the energies of teachers towards a better understanding of why, when and how students become better learners.

Again, the researcher wants to state emphatically that an action research is a "clinical" research and for that matter when a problem is identified and established, all obtainable means must be used to help remedy the situation. Action Research is a process designed to empower all participants in the educational process with the means to improve the practices conducted within the educational experience (Hopkins,1993). Action research has been described as an informal, qualitative, formative, subjective, interpretative, reflective and experiential model inquiry in which all individuals involved in the study are new and contributing participants (Hopkins, 1993).

To address the different research questions, the researcher used different methods. It is assumed that teachers and students work best on problems they identified for themselves. Teachers become more effective when encouraged to examine and assess their own work and to 
consider ways of doing it differently and working with colleagues to help each other in their professional development. It is a quest for knowledge about how to improve. It also involves people working to improve their skills, techniques and strategies. It is about how we can change our instruction to impact positively on students.

\section{Study Population}

The study was carried out at Yamfo Anglican Senior High School in Tano North District of the Brong Ahafo Region of Ghana.The area of study was chosen because the performance in mathematics for the district has been experiencing a downward trend as compared to other neighbouring distrcts.

The targeted population for the research was Yamfo Anglican Senior High School students in the Tano North District of the Brong and Ahafo Region of Ghana. Yamfo Anglican Senior High School has a population of six hundred and seventy- eight (678) students, with a teaching staff of fifty-six (56) and non-teaching members of thirty (30).

\section{Sample and Sampling Technique}

In this study, non - probability sampling was used, in particular convenience sampling. These were employed because of inadequate logistics, financial constraints and easy accessibility. Form three science and Form three Agricultural classes were selected for the study because the researcher teaches in those classes and that was where the problem existed. In studies of this nature, sampling is usually non - probability, convenient, purposeful and small (Apaw, 2009). The sample size is 41 students of which 8 were girls and 33 were boys.

\section{Research Instruments}

Considering the nature of research questions being examined, the instruments used for the collection of data were questionnaire, pre-test and post-test.

The questionnaires were to find out Students perception about the use of the scientific calculators and students' rate of competence with the use of the scientific calculator. The pre -test and post-test were also meant to find out whether the scientific calculator could improve students' computational skills in mathematics of Yamfo Anglican Senior High School.

The checklist for determining computational errors, questionnaire, pre-test and post-test questions were further cross-checked and corrections made, after which they were administered.

\section{Reliability and Validity}

Reliability is the extent to which results are consistent over time and also accurate representation of the total population understudy. The research instrument were reliable and concerns the extents to which instrument yields the same results on repeated trails.

Validity is the extent to which an instrument measures what it is supposed to measure and performs as it is designed to perform; that is, the degree to which any measurement approaches or succeeds in describing or quantifying what it is designed to measure. For this research work the content validity of the instruments; that is questionnaire, pre - test and post - test was determined by experts in mathematics education and necessary corrections and suggestions made. The use of these three instruments for the data collection reflects methodological validity in triangulation.

\section{DATA ANALYSIS AND RESULTS}

\section{Analysis Procedure}

Data was collected using both qualitative and quantitative methods, also known as the mixed method approach. This is called the mixed method explanatory study (Harrison\& Reilly, 2011). It is used by combining quantitative and qualitative methods to explain a situation which gave an indepth analysis of one or more events, setting programmes or other bounded systems. The collected data was analyzed using paired sample test with SPSS.

Table 4. 1 Descriptive statistics of the post - test and the pre - test scores

\begin{tabular}{cccc}
\hline Pair Sample Test & N & Mean & Standard Deviation \\
\hline Pre-test & 41 & 40.78 & 17.984 \\
Post-test & 41 & 51.58 & 18.252 \\
\hline
\end{tabular}

Source: Field survey, 2014

From the table above the mean marks obtained for the pre test was 40.78 and that of the post - test was also found to be 51.58. This indicates that, before the introduction of the intervention, averagely all the students scored 40.78 in their test examinations which is observed to be on the low side as compared to the marks scored by the students after the intervention was introduced.

Since the two test marks considered are paired (that is one depending on the other), the researcher deemed it necessary to quantify the strength of the relationship or dependence between the two-mark samples. 
In order to really establish whether there exists any difference or not between the two sample marks, paired $\mathrm{t}$ test was used to test the null hypothesis.

There is no significant difference between the means of the pre - test and the post - test marks scored.
From Table 4.2 with a $95 \%$ confidence interval, mean difference of -10.800 , standard deviation of 2.710 , the t-test statistics of -25.206 as well as the $p$-value $<\alpha$-value indicates that the null hypothesis must be rejected.

Table 4. 2 Results of paired sample test

\section{Paired Samples Test}

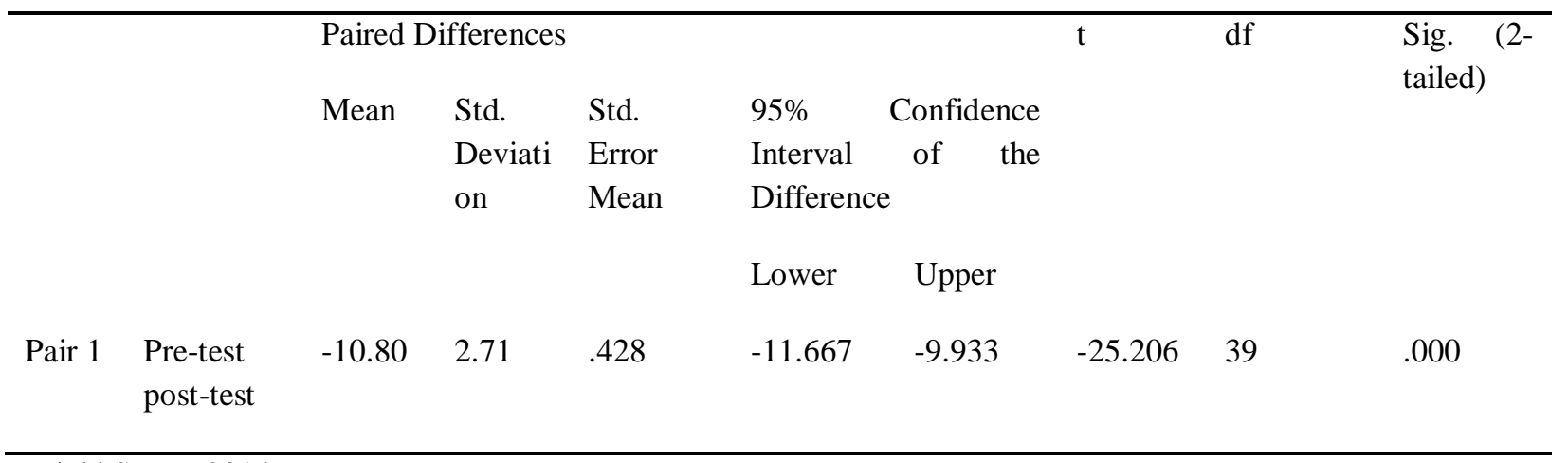

Field Survey2014

The table 4.2 above, shows the output of the paired sample $t$ - test, the mean difference of -10.800 , the standard deviation of 2.710 , the $95 \%$ confidence interval for the mean difference, the $\mathrm{t}$ - test statistics of -25.206 as well as the $\mathrm{p}-$ value of $\operatorname{sig} 2$ - tailed of 0.000 were obtained. By the rule we reject the null hypothesis if $\mathrm{p}-$ value $<\alpha$. From table 4.2 above the $\mathrm{p}-$ value $=0.000<\alpha=0.05$, hence we reject the null hypothesis of no mean difference and conclude that there exist significant difference between pre - test and post - test marks. This further explained that the introduction of the intervention, that is, calculator has brought about improvement in students' performance in mathematics than the previous mathematical tables or working mathematics without calculator. Hence calculator brings about students' mathematical achievement.
From the table above, the Pre-test had a mean score of 40.78 $(s d=17.984)$ and the Post-test had a mean score of 51.58 $(s d=18.252)$. The difference in the mean scores of the pretest and Post-test was found to be significant $(t=-25.206$; $d f=39 ; \mathrm{p}=0.000$ ), therefore the use of the calculator has a positive effect on Yamfo Anglican Senior High School students' computational skills.

4.2 What difficulties do Yamfo Anglican SHS Students' have in the use of scientific calculators?

The second research question raised for the study was to examine what difficulties students of Yamfo Senior High School have in using the calculator. Some of the difficulties identified were used of Sequence of operations, approximations, appropriate use of parenthesis and application of concepts.

Difficulties in the use of parenthesis

Most of the students exhibited difficulties in the used of parenthesis. For example, students were asked to

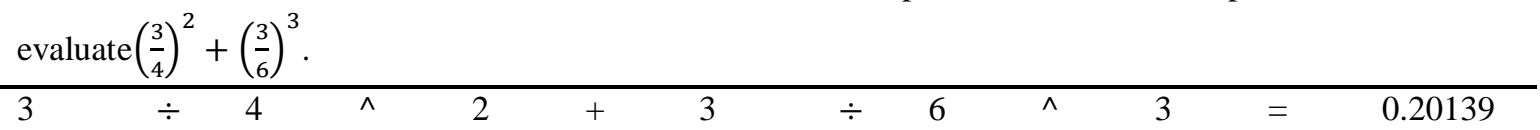
It would be realized that most of the students ignored the parenthesis. The correct answer should have been

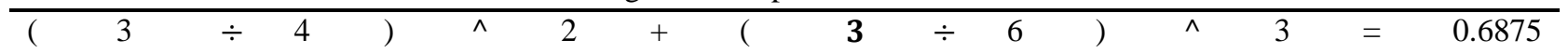




\section{Difficulties in the used of approximations}

Another difficulty student exhibited were the approximation. For instance, students were asked to find the value of $\left(\frac{\sin 60}{\cos 60}\right)$ to two decimal places. Most of the students $\sin 60 / \cos 60=1.7320$ most of the students could not approximate their answers, which affected their answers. The correct answer should have been

\begin{tabular}{llllll}
\hline $\operatorname{Sin} 60$ & $\div$ & Cos60 & 1.73205 & $\cong$ & 1.73 \\
\hline
\end{tabular}

\section{Difficulties in the use of sequence of operation}

Furthermore, another difficulty most of the form three students of Yamfo Anglican Senior High School faced was the used of sequence of operations. For instance, students were asked to solve $\frac{8.100 \times 0.0014}{5.60 \times 0.0018}$
This was how students approached the question $((8.100 \times 0.0014) \times(5.60 \times 0.0018))=0.000114$

In fact, most of the students do not follow the sequence of operations which affected their answers. The correct process should have been $((8.100 \times 0.0014) \div(5.60 \times 0.0018))=$ 1.125

\section{Difficulties in concept application}

Another difficulty encountered by students was concept application. Most of the students applied the wrong concept which affected their answers. For example, when students were given a question and asked to find the value of $\cos ^{-1} \frac{\sqrt{3}}{2}$. Students approached to the question were:

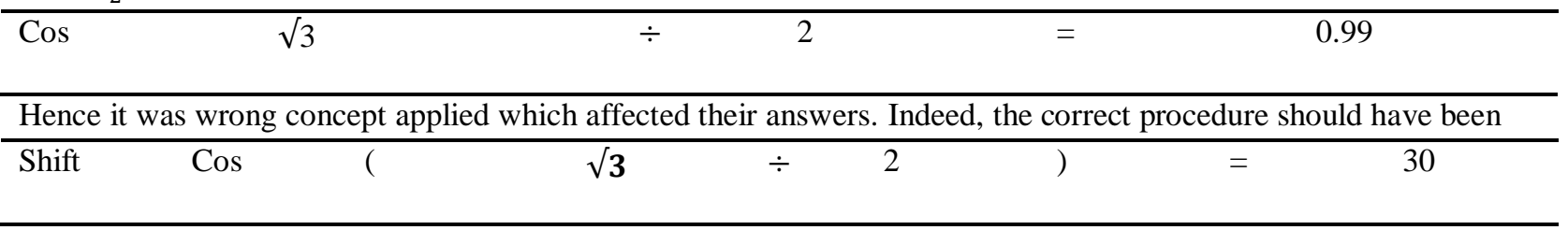

From the discussion above it is clear that students of Yamfo Anglican Senior High School difficulties were the use of parenthesis and operational sequence. Also some were approximation and concept application. After they were taken through the use of the calculator most of the students did better in the post-test.

Table 4. 3 Summary of valid responses

\begin{tabular}{ccc}
\hline Valid Responses & Frequency & Percentage \\
\hline YES & 22 & 53.7 \\
NO & 19 & 46.3 \\
\hline Total & $\mathbf{4 1}$ & $\mathbf{1 0 0}$ \\
\hline
\end{tabular}

From the table 4.3 above, a total of 41 students (respondents) showed whether they face difficulties or not when using the calculator in solving mathematics problems.22 students / respondents representing $53.7 \%$ chose YES to indicate that they encountered difficulties in the use of the calculators in solving mathematics problems at Yamfo Anglican Senior High School. 19 students / respondents representing $46.3 \%$ chose NO to indicate that they do not face difficulties when using calculators in solving mathematics problems at Yamfo Anglican Senior High School. The difference in the percentages showed that most of the students did not have difficulty in solving mathematics problems when they use calculators.

Yamfo students' rating of their perception about calculator usage

Table 4.3 indicates how Students of Yamfo Anglican Senior High School perceive calculator as devises that will help them solve mathematics questions 
faster and with ease. Out of 41 respondents with a mean of 4.90 and standard deviation of 0.300 hold the view that with the aid of calculator they would be able to solve mathematics questions faster and with Table 4. 4 students' rating of their perception of the use of calculator usage ease. Most of the students/ respondents agree to the fact that lazy students manipulate calculators to find answers to mathematics problems without really showing the necessary steps.

\section{$\begin{array}{llll}\text { STUDENT RESPONSE } & \text { N } & \text { MEAN } & \text { STD. DEV. }\end{array}$}

I perceive calculator as devises that will help me solve mathematics questions faster and with ease

$\begin{array}{lll}41 & 4.90 \quad .300\end{array}$

I have formed opinion that the use of scientific calculator will aid my learning and understanding of mathematics problems

I can easily solve mathematics problems because I can effectively use calculator

$\begin{array}{lll}41 & 3.73 & 1.467\end{array}$

Lazy students manipulate calculators to find answers to mathematics problems without really showing the necessary steps.

I waste my time in solving mathematics problems because I do not really know how to use calculators effectively.

Field data 2014

Total of 41 students / respondents from Yamfo Anglican Senior High $(m=4.90)$ hold the view that calculators as device would help them solved mathematics questions faster and with ease. Most the respondents $(m=3.95)$ are of the opinion that the use of scientific calculator will aid their learning and understanding of mathematics problems. Also, most respondents $(m=3.24)$ which correspond to a percentage of 58.5 agree that lazy students manipulate calculators to find answers to mathematics problems without really showing the necessary steps. This goes to buttress the famous Chinese proverb as rightly paraphrase by Smith (1997), in respect to the usefulness of the calculator: "Tell me mathematics and I forget, show me mathematics and I may remember, involve me and I will understand mathematics". It was therefore, not suprising when one of the Students of Yamfo Anglican Senior High School during conversation said" if our teachers will make sometime and teach us how the scientific calculator can be used to the maximum, then we can use it in our examinations and not have problems in using this effective tool. Also, if the scientific calculator can constantly be taught it will bring maximum benefits to us, which will improve our performance in mathematics".

This implies that the level of achievement in learning mathematical concepts by Students of Yamfo Anglican Senior High School is higher when students are taught how to use effectively the scientific calculator during their examinations or achievement test.

In sum this chapter presented the results, findings and discussions of investigating the effective use of scientific calculator on students' mathematical achievement in Yamfo Anglican Senior High School.

\section{DISCUSSION OF FINDINGS}

From the analysis it is clear that Ghanaian text books and syllabuses designed contained less problems that required the use of calculators to enhance the computational skills. It can be concluded that the Ghanaian text books and syllabuses experienced by students' place much more emphasis on number work rather than developing students' computational abilities and skills.

In addition, Mereku et al (2007, p 57), in a report of Ghana National Working party on the use of calculators in the 
BECE mathematics paper also concluded that calculators are effective aids when it comes to problem solving, reinforcement of computational skills, pattern recognition and number sense. Calculators also help in the teaching of topics such as fractions, taxations, integers, perimeter, areas, to mention a few. They also found that there was no loss in students' ability to perform paper and pencil computational skills when calculators were used as part of mathematics instruction.

Research question two looked at the difficulty's students' of Yamfo Anglican SHS have in using the calculator. From the research some of the difficulties exhibited by Yamfo Anglican SHS students included the used of sequence of operations, approximations, application of concepts and the use of parenthesis. One-week intervention was organized to help students overcome their problem with the used of the scientific calculator. These saw improvement in students' performance their post - text, indicating that the difficulties have been overcome.

Research question three was to find out how students' of Yamfo Anglican SHS perceive the use of the calculators in mathematics. From the research with $(M=4.90 S D=0.300)$ hold the view that calculators as device would help SHS students' solved mathematics faster and with ease. Also ( $M$ $=3.24, S D=1.463$ ) hold the perception that lazy students manipulate calculators to find answers to mathematics problems without really showing the necessary steps. Furthermore, from the research $(M=3.95, S D=1.224)$, most of the students were of the opinion that the used of scientific calculator would aid their learning and understanding of mathematics problems. The finding is consistent with similar studies carried out in different countries. For instance, Waite (2004) found that even though teachers show great interest and motivation to teach students' the used of calculators, in practice, the used of calculators is still very low among students. Therefore, teachers of mathematics should use calculators often so that students would develop interest in its usage, because calculators give students access to powerful new ways to explore concepts.

\section{CONCLUSIONS}

Results of the study showed that calculators were effective in improving students' computational skills. Calculators help students to assess the reasonableness of their answers, to justify their answers and then to form conclusions. Calculators in any way did not hinder students' ability to solve problems or their reasoning and computational abilities or skills. It does not seem, then that students who use scientific calculators throughout their study becomes overly reliant on the calculator, since there were some topics in the mathematics syllabus for Senior High School level which is more abstract and theoretical and heavily founded on the basis of deductions. For this reason, any student who enters these institutions of higher learning is expected to think and use the scientific calculator so as to be able to solve problems.

Results from the qualitative aspect clearly show that when students were asked whether they think the use of calculator makes mathematics simple and easy; about 97.6\% respondents said yes as against $2.4 \%$ respondents of forty one. However, more than half of the respondent said they have difficulty in using the calculator. Also $78.0 \%$ of the respondents said they require extra help on the usage of calculator. The observation made in this study, collaborates earlier findings of Anamoah - mensah and Mereku(2005) who also observed that the Ghanaian curriculum text books experienced by the students who participated in the TIMSS - 2003, placed a great deal of emphasis on number work and knowledge of facts and procedures. It can therefore be argued that the poor performance of the Ghanaian students can be attributed largely to the lack of congruence between what is emphasized in the mathematics curriculum in Ghana and what is currently valued globally in school mathematics.

\section{REFERENCES}

[1] Anamuah-Mensah, J. (2002). Chairman of Educational Reforms Review Committee. University of Education, Winneba.

[2] Anamoah-Mensah \& Mereku D. K. (2005). Ghanaian Junior High School 2 students' Abysmal Mathematics Achievement in TIMSS - 2003; A consequence of the Basic School Mathematics Curriculum. Mathematics Connection Volume 5, p 1-13.

[3] Anku, S. (2011). Make mathematics a friendly-subject. By Ghana News Agency (GNA).

[4] Apaw, J. (2009). The use of information and communication technology in the teaching of mathematics in colleges of education in Ghana. Master's thesis in mathematics education, University of Education, Winneba

[5] Bayetto, A. \& Yate, S. M. (2009). Teachers' views of calculators for Students with Learning Disabilities. Flinder University. Adeliade. Australia. Retrieved on march3,2008 from http://www.aare.edu.au/07pap/bay07481.pdf.

[6] British Broadcasting cooperation (2006, july24). How Maths can be great fun. Retrieved August20th,2010from http://www.heymath.net/heymath\%20in\%20the\%20BBC\%20N ews.pdf.

[7] Catalanello, R. (2003, November 23). Calculating the impact. St. Petersburg Times, p1B.

[8] Curriculum Research Development Division (2007). Teaching Syllabus for Senior High School Mathematics.

[9] Dancis, J. (2004, may 27). Calculators 'Pretend' exam add up to poor math skills. The Washington Post, $\mathrm{p} 4$

[10] Doerr, H.M. \& Zangor, R. (2000). Creating Meaning for and with the graphing calculator. Educational Studies in Mathematics, 42(1),35 - 39.

[11] Frances, W. Economist's View "The mathematics generation gap" Main links for 2011- 05- 30. http://www.solvingstonehenge.co.uk/page3html.

[12] Government of India (2009). National Policy on ICT in School Education. ICT in School Education pages 5- 7. 
Ministry of Human Resource Developments, Department of School Education and Literacy.

[13] Harison, R. L. \& Reilly, T. M. (2011). Mixed methods design in marketing research in qualitative market research: An International Journal Volume 14(1) pp 7- 26. Emerald Group publishing Limited. Retrieve from http://www.emeraldinsight.com/Journals.htm?articleid=190290 $7 \&$ show $=$ html.

[14] Hopkins D. (1993). A teacher's guide to classroom research, $2^{\text {nd }}$ edn .Buckingham: Open University press.

[15] Hunter J, (2011) 'The effects of Graphing calculator use on High - School Students' Reasoning in integral calculus". University of New Orleans Thesis and Dissertations, paper 1346.

[16] Laura, C. (2012). Primary Schools to ban calculators because children have become too dependent on them. Published by the daily Mail.UK. Retrieved on16th, June 2014, from http://www.gov.uk/government/news/government-banscalculators-in-tests-for-11-years-olds

[17] Mereku, D. K. (1992). School Mathematics the Misplaced Emphasis; The People's Daily Graphic, September 19, 1992.

[18] Mereku, D. K., Donkor, J., Sokpe, B., Addo, G. K., Klave, M. K., Incoom, P. K. \& Wilson, R. (2007). Report of the Ghana National Working Party on the use of calculators in the Basic Education Certificate Examination (BECE), Mathematics Paper p57 - 60. In Mathematics Connection, vol.6

[19] Miller, C. A. (2007). "Action Research: Making Sense of Data" On - line article, retrieved from http://www.coe.fau.edu/sfce/sensdata.htm.

[20] Mullis I.V. S, Martins, M. O, Foy, P. \& Arora, A. (2012). TIMSS (2011). International results in mathematics, USA TIMSS \& PIRIS International study centre and The Netherlands: IEA.

[21] National Council of Teachers of Mathematics (1989). Curriculum and Evaluation Standards for School Mathematics. Reston, VA: NCTM. Retrieved on july10,2010 from http://www.mathgoodies.com/articles/problemsolvinghtml.

[22] National Council of Teachers of Mathematics (2000). Principles and Standards for School mathematics. Reston, VA: NCTM. Available on line at http://standards.nctm.org.
[23] Shamatha, J. H. Peressini, D. \& Meymaris, K. (2004). Technology - supported mathematics activities situated within an effective learning environment theoretical frame work. Contemporary issues in technology and teacher education [on line series],3(4). Retrieved from http://www.citejournal.org/vol3/ics4/mathematics/article.cfm11 $\underline{6}$.

[24] The Association of Mathematics Teacher Educators (2006). Preparing teachers to use technology to enhance the learning of mathematics. Retrieved from http://www.amte.net/Approved\%20AMTE\%20Technology\%20 position\%20paper.pdf.

[25] Turner, S. \& Yidana, I. (2004). Information and Communications Technology: The bedrock of sustainable development. Retrieved from http://www.dgroups.org/groups/ginks/attach/ginks/135688/articl e.doc?ois $=$ no

[26] Waite, S. (2004). Tools for the job: A report of two surveys of information and communications technology training and use for literacy in primary schools in the West of England. Journal of computer Assisted Learning 20,11 - 21.

[27] West Africa Examination Council Chief Examiners Report 2008, p13.

[28] West Africa Examination Council (2014). Rules and Regulation for Invigilators and Supervisors - Accra - WAEC.

[29] Willis, S. \& Kissane, B. (1989). Computing Technology in Education in Mathematics. In Department of Employment, Education and Training, Discipline, Review of Teacher Education in Mathematics and Science, Volume3,57-92. Canberra: Australian Government Publishing Service.

[30] Wu, Z., An, W. \& Wang, L. (2005, August). Comparison study of integrating technology in mathematics Teacher's Knowledge and confidence between United States and Chinese Teachers. Paper presented at the symposium on Technology and Teaching at the third East Asia Region Conference on Mathematics Education, Shanghai, Nanjing and Hangzhou, China.

Adam Mumuni Jeremiah, Department of Mathematics, Bagabaga College of Education, Box 35 ER Tamale-Ghana. 